\title{
CMR substances in consumer products: from food contact materials to toys
}

\author{
Ariane Lenzner $^{1} \cdot$ Bärbel Vieth ${ }^{1} \cdot$ Andreas Luch $^{1}$
}

Received: 2 March 2018 / Accepted: 6 March 2018 / Published online: 16 March 2018

c) Springer-Verlag GmbH Germany, part of Springer Nature 2018

\section{Introduction}

Good news first: toys must be safe! According to Directive 2009/48/EC on the safety of toys (Toy Safety Directive, TSD), substances classified as carcinogenic (Carc), mutagenic (Mut), or toxic for reproduction (Rep) category 1A, $1 \mathrm{~B}$, or 2 (so-called "CMR" substances), shall not be used in toys or components thereof. However, exemptions to this rule do exist. One of them stated that toy materials complying with the requirements laid down in Regulation (EC) No. 1935/2004 for Food Contact Materials (FCMs) are excluded from the prohibition, actually resulting in a higher level of protection (cf. below). However, this exemption expired on July 20, 2017. At present, only a few substances are listed in Appendix C to Annex II of the TSD and were thus specifically regulated. All remaining CMR substances, despite the ban, might be present in toys up to the maximum concentration to which they were classified as CMR according to CLP regulation (EC) No. 1272/2008 (EU 2008). For mutagenic or carcinogenic substances category $1 \mathrm{~A}$ and $1 \mathrm{~B}$, this usually means a concentration of up to $0.1 \%$ ( $0.3 \%$ for those toxic to reproduction), while category 2 substances could be present at concentrations of up to 1\% (Carc2 and Mut2) and 3\% (Rep2), respectively. Noteworthy, these limit values were not derived based on toxicological risk assessments. Now, after July 20, 2017, these limits also apply to those materials for which the exemption based upon the requirements of the FCM Regulation was formerly valid. But what are the consequences? Did the exemption imply a higher safety level for the children in Europe in the recent past? Or was it, indeed, dispensable and thus okay not to extend it? Here,

Andreas Luch

Andreas.Luch@bfr.bund.de

1 Department of Chemical and Product Safety, German Federal Institute for Risk Assessment (BfR), Max-Dohrn-Strasse 8-10, 10589 Berlin, Germany we try to address this issue by providing risk assessments of four exemplarily chosen substances.

\section{Regulation of food contact materials (FCMs) and comparison with toys}

Regulation (EC) No. 1935/2004 defines general requirements for materials and articles intended to come into contact with food (EU 2004). This framework regulation is accompanied by individual measures for different types of materials: Regulation (EU) No 10/2011, for instance, lays down specific measures for plastic materials and articles intended to come into contact with food (Plastics Implementation Measure, PIM; EU 2011). Annex I of this regulation contains a list of all relevant monomers, starting materials, microbial fermentation macromolecules, additives, and adjuvants authorized for plastic materials with food contact, as well as specific migration limits or other restrictions and specifications. Important to say, these substances (and the list compiles more than 1000 of them) were individually assessed by the European Food Safety Authority (EFSA) prior to their approval. Here, the monomers listed in PIM 10/2011 have been checked for harmonized classification as CMR substance according to CLP regulation (EC) No. $1272 / 2008$ and their significance in the production of toys. As a result, 20 relevant substances could be extracted as being carcinogenic, mutagenic, or toxic for reproduction (see Table 1).

Specific regulations for monomers used in toys currently exist for 5 of the above-listed substances only. These are either regulated in Appendix C to Annex II of TSD 2009/48 (EU 2009) or in the non-harmonized European Standard EN 71 part 9 to 11 . For example, a specific migration limit of $0.1 \mathrm{mg} / \mathrm{l}$ for bisphenol A in toys has already been defined in EN 71-9 as well as in Appendix C to Annex II of the TSD. Moreover, in November 2016, Member States of the European Union adopted the migration limit for bisphenol 
Table 1 Compilation of monomers as listed in Annex I of Regulation (EU) No. 10/2011 (plastics implementation measure, PIM), its classification as CMR substances according to CLP regulation (EC) No.
$1272 / 2008$, and its maximum concentration/migration limits permitted in toys (according to the Toy Safety Directive, TSD, or the nonharmonized European standards EN 71-9 to 11)

\begin{tabular}{|c|c|c|c|c|c|c|c|}
\hline \multirow[t]{2}{*}{$\#$} & \multirow[t]{2}{*}{ CAS-No. } & \multirow[t]{2}{*}{ Name } & \multicolumn{2}{|c|}{ EU 10/2011 (PIM) } & \multirow{2}{*}{$\begin{array}{l}\text { (EC) No } 1272 / 2008 \\
\text { (CLP) } \\
\text { Classification }\end{array}$} & \multicolumn{2}{|c|}{ 2009/48/EC (TSD) or EN 71-9 to 11} \\
\hline & & & $\begin{array}{l}\mathrm{SML}^{\mathrm{a}}(\mathrm{mg} / \\
\mathrm{kg} \text { of food) }\end{array}$ & $\begin{array}{l}\text { Other restrictions }{ }^{\mathrm{b}} \\
\text { (mg/kg of final } \\
\text { product) }\end{array}$ & & Content limit (\%) & $\overline{\text { Migration limit }(\mathrm{mg} / \mathrm{l})}$ \\
\hline 1 & $80-05-7$ & Bisphenol A & 0.6 & & $\operatorname{Rep}_{1} \mathrm{~B}^{\mathrm{c}}$ & 0.3 & $0.1^{\mathrm{d}}(0.04)^{\mathrm{e}}$ \\
\hline 2 & $108-95-2$ & Phenol & 3 & & $\operatorname{Mut} 2^{\mathrm{f}}$ & $1(10 \mathrm{mg} / \mathrm{kg})^{\mathrm{g}}$ & $15^{\mathrm{h}}(5)^{\mathrm{i}}$ \\
\hline 3 & $50-00-0$ & Formaldehyde & 15 & & $\begin{array}{l}\text { Carc1B } \\
\text { Skin Sens } 1^{\mathrm{k}}\end{array}$ & $0.1(0.05)^{1}$ & $1.5^{\mathrm{m}}$ \\
\hline 4 & $75-01-4$ & Vinyl chloride & $\mathrm{NN}^{\mathrm{n}}$ & 1 & Carc1A & 0.1 & \\
\hline 5 & $106-99-0$ & 1,3-Butadiene & $\mathrm{NN}^{\mathrm{n}}$ & 1 & Carc1A, Mut1B & 0.1 & \\
\hline 6 & $75-21-8$ & Ethylene oxide & $\mathrm{NN}^{\mathrm{n}}$ & 1 & Carc1B, Mut1B & 0.1 & \\
\hline 7 & $75-56-9$ & Propylene oxide & $\mathrm{NN}^{\mathrm{n}}$ & 1 & Carc1B, Mut1B & 0.1 & \\
\hline 8 & $78-79-5$ & $\begin{array}{l}\text { 2-Methyl-1,3-buta- } \\
\text { diene }\end{array}$ & $\mathrm{NN}^{\mathrm{n}}$ & 1 & Carc1B, Mut2 & 0.1 & \\
\hline 9 & $106-89-8$ & Epichlorohydrin & $\mathrm{NN}^{\mathrm{n}}$ & 1 & Carc1B & 0.1 & \\
\hline 10 & $107-13-1$ & Acrylonitrile & $\mathrm{NN}^{\mathrm{n}}$ & & Carc1B & 0.1 & \\
\hline 11 & 79-06-1 & Acrylamide & $\mathrm{NN}^{\mathrm{n}}$ & & Carc1B, Mut1B, Rep2 & 0.1 & action limit, i.e., $0.02^{\circ}$ \\
\hline 12 & $151-56-4$ & Ethyleneimine & $\mathrm{NN}^{\mathrm{n}}$ & & Carc1B, Mut1B & 0.1 & \\
\hline 13 & $584-84-9$ & $\begin{array}{l}\text { 2,4-Toluene-diisocy- } \\
\text { anate }\end{array}$ & $\mathrm{NN}^{\mathrm{n}}$ & $1^{\mathrm{p}}$ & Carc2Skin Sens1 & 1.0 & \\
\hline 14 & $5873-54-1$ & $\begin{array}{l}\text { 2,4'-Methylene-diphe- } \\
\text { nyl diisocyanate }\end{array}$ & $\mathrm{NN}^{\mathrm{n}}$ & $1^{\mathrm{p}}$ & $\begin{array}{l}\text { Carc2 } \\
\text { Skin Sens1 }\end{array}$ & 1.0 & \\
\hline 15 & $123-31-9$ & Hydroquinone & 0.6 & & $\begin{array}{l}\text { Carc2, Mut2 } \\
\text { Skin Sens1 }\end{array}$ & 1.0 & \\
\hline 16 & $108-05-4$ & Vinyl acetate & 12 & & Carc2 & 1.0 & \\
\hline 17 & $75-35-4$ & Vinylidene chloride & $\mathrm{NN}^{\mathrm{n}}$ & & Carc2 & 1.0 & \\
\hline 18 & $108-45-2$ & 1,3-Phenylenediamine & $\mathrm{NN}^{\mathrm{n}}$ & & Mut2 & 1.0 & \\
\hline 19 & $110-88-3$ & 1,3,5-Trioxane & 5 & & Rep2 & 3.0 & \\
\hline 20 & $100-42-5$ & Styrene & - & & Rep2 & 3.0 & $0.75^{\mathrm{q}}$ \\
\hline
\end{tabular}

${ }^{a}$ SML (mg/kg): Specific migration limit of Regulation (EU) No. 10/2011, expressed in mg of substance per kg of food

${ }^{\mathrm{b}}$ According to Regulation (EU) 10/2011, this column contains other restrictions than the SML specifically mentioned and which are related to the substance

${ }^{\mathrm{c}}$ Known (category 1A), presumed (category 1B), ore suspected (category 2) human reproductive toxicant

${ }^{\mathrm{d}}$ Migration limit value for bisphenol A in toys as listed in Appendix C to Annex II of the TSD and EN 71-9, currently effective

${ }^{\mathrm{e}}$ Migration limit value for bisphenol A in toys to be listed in Appendix C to Annex II of the TSD, applying from November 26, 2018 onwards

${ }^{\mathrm{f}}$ Substances known (category 1A and 1B) or which cause concern (category 2) to induce heritable mutations (and/or heritable mutations in the germ cells) of humans. Category $1 \mathrm{~A}$ is based on positive evidence from human epidemiological studies, while category $1 \mathrm{~B}$ is based on positive result(s) from animal tests in vivo

${ }^{\mathrm{g}}$ Content limit for phenol as a preservative

${ }^{\text {h}}$ Migration limit value for phenol in toys as listed in Appendix C to Annex II of the TSD and EN 71-9, currently effective

${ }^{\mathrm{i}}$ Migration limit value for phenol in toys to be listed in Appendix C to Annex II of the TSD, applying from November 4, 2018 onwards

${ }^{j}$ Substances known (category 1A), presumed (category 1B), or suspected (category 2) to have carcinogenic potential for humans

${ }^{\mathrm{k}}$ Substances that may lead to an allergic response following skin contact

${ }^{1}$ Content limit for formaldehyde as a preservative

${ }^{\mathrm{m}}$ Restricted to migration of the formaldehyde monomer from polymeric toy materials

${ }^{\mathrm{n}} \mathrm{NN}$ : Transition of the substance into food must not be detectable by a sensitive method

${ }^{\circ}$ Migration limit for acrylamide as given in EN 71-9 to 11

${ }^{\mathrm{p}}$ Expressed as isocyanate moiety

${ }^{\mathrm{q}}$ Migration limit for styrene as listed in EN 71-9 
A to the provisional TDI of EFSA and lowered the limit value to $0.04 \mathrm{mg} / \mathrm{l}$ in accordance with the methods laid down in EN 71-10:2005 and EN 71-11:2005. These provisions shall apply starting from November 26, 2018 (EU 2017a). In addition, a content limit of $0.3 \%$, that is, $3000 \mathrm{mg} / \mathrm{kg}$ for substances toxic for reproduction category $1 \mathrm{~B}$ applies. For phenol, a migration limit of $5 \mathrm{mg} / \mathrm{l}$ in polymeric materials has recently been legislated and will apply starting from November 4, 2018 (EU 2017b). Finally, for formaldehyde, an emission limit of $0.1 \mathrm{mg} / \mathrm{m}^{3}$ for toys made of resinbonded wood material and content limits for further toy materials like textiles, paper, and water-based toy materials for inclusion in Appendix C to Annex II of the TSD are under discussion. In addition to these three substances, migration limits for acrylamide (action limit) and styrene $(0.75 \mathrm{mg} / \mathrm{l})$ are laid down in the non-harmonized European standard EN 71-9:2007 (Table 1).

Bisphenol A, phenol, and formaldehyde are excluded from our analysis, since they are already listed in Appendix $\mathrm{C}$ or soon will be. For the remaining 17 substances of Table 1, specific migration limits between "non-detectable" (i.e., $<10 \mu \mathrm{g} / \mathrm{kg}$ food) and $12 \mathrm{mg} / \mathrm{kg}$ (for vinyl acetate), respectively, apply to FCMs. That means, transition from the FCM into the containing food shall either be analytically non-detectable or must not exceed the stated maximum value, respectively. In addition to these specific migration limits, further requirements are laid down in Regulation (EU) No. 10/2011 for 8 of the remaining 17 substances, after which only up to $1 \mathrm{mg}$ of residual monomer content per $\mathrm{kg}$ of FCM may be present (see Table 1). This mainly concerns monomers which are known to be carcinogenic in humans, i.e., category $1 \mathrm{~A}$, carcinogens with a genotoxic mechanism of action (presumably no threshold), and substances which were additionally classified as strong allergens.

Even though the significance for human health is less known and/or likely for category 2 substances, implying a lower toxicity and/or a threshold-based mechanism, the ten times higher content limit compared to category 1 substances is arbitrary and does not adhere to scientific data (SCHER 2010). In comparison to the corresponding limit values in FCMs, the residual content permitted for some monomers in toys is higher by a factor of 1000 (Table $1, \# 4$ to \#9; $1 \mathrm{mg} / \mathrm{kg}$ vs. $0.1 \%=1000 \mathrm{mg} / \mathrm{kg}$ ) or 10,000 (Table 1 , $\# 13$ and \#14; $1 \mathrm{mg} / \mathrm{kg}$ vs. $1 \%=10,000 \mathrm{mg} / \mathrm{kg}$ ).

\section{Regulation of CMR substances in toys}

According to the TSD, CMR substances shall not be used in toys, in components of toys, or in micro-structurally distinct parts of toys. As mentioned earlier, several exemptions to this rule exist. Apart from the "FCM exemption", which is no longer valid, there are a number of additional provisions on how to circumnavigate the otherwise laudable ban. For example, CMR substances (or mixtures) can be present in toys, as long as they are inaccessible to children in any form, including inhalation, when the toy is used as intended or in a foreseeable way, bearing in mind the behavior of children. Another exemption applies if the substance or mixture and its use or exposure has been evaluated as safe by the Scientific Committee, permitted, and listed in Appendix A of Annex II (list of CMR substances and their permitted uses). To date, this list contains only one substance, nickel (Carc2) in stainless steel, and electrical conducting parts. Last but not least, Appendix C of Annex II lists specific limit values for chemicals including CMR substances used in toys intended for use by children under 36 months or in toys intended to be placed in the mouth and, for instance, already contains the substances bisphenol A and phenol, while inclusion of formaldehyde is under discussion. Last but definitely not least, CMR substances might, nevertheless, be present in toys, as mentioned at the beginning, up to the maximum concentration to which they were classified as CMR according to CLP regulation (EC) 1272/2008 (EU 2008).

\section{The principle of the additional acceptable lifetime cancer risk}

In general, when assessing carcinogens with a genotoxic mode of action, the ALARA principle should be applied, that is, reaching a concentration limit "as low as reasonably (i.e., technologically) achievable". In 2010, the Scientific Committee on Health and Environmental Risks (SCHER) evaluated the risks of CMR substances in toys and concluded that, ideally, human carcinogens (category 1A and 1B), for which no threshold could be derived, should not be present in toys as intentionally used compounds. Thus, as solely acceptable approach, SCHER proposed an acceptable additional lifetime cancer risk of $1 \times 10^{-6}$ (that is, 1 additional cancer case in 1,000,000 individuals exposed to that dose) in adults for the assessment of genotoxic carcinogens, and recommended that an additional safety factor might be considered for children, especially those younger than 36 months (SCHER 2010).

\section{Assessing cancer risks from exposures during childhood only}

Because of their mouthing behavior, it is assumed that young children up to 3 years of age ingest up to $8 \mathrm{mg}$ scrapable toy material per day, which is the default assumption of the TSD. The resulting systemic exposure dose (SED) after oral ingestion of toy material containing residual monomers can be estimated using the following equation: 
$\mathrm{SED}=\frac{C\left[\frac{\mathrm{mg}}{\mathrm{mg}}\right] \times \mathrm{IA}[\mathrm{mg} / \mathrm{day}] \times \mathrm{R} \times \mathrm{GIA}}{\mathrm{bw}[\mathrm{kg}]}$

where $\mathrm{C}=$ concentration of the CMR substance in the toy material (TSD or 10/2011 PIM, respectively), IA = daily ingested amount, here: $8 \mathrm{mg}$ of scrapable toy material per day as default value according to TSD, $\mathrm{R}=$ release of monomer into gastrointestinal juice after ingestion, here: $1(100 \%$, worst-case), GIA = absorption through the gastrointestinal tract, e.g., 1 ( $100 \%$, worst-case), bw = body weight, here: $7.5 \mathrm{~kg}$ for children age $0-3$ years as default value according to TSD

Most current cancer assessment approaches associated with less-than-lifetime exposures to non-threshold carcinogens involve averaging the short period of exposure, i.e., mouthing during the early childhood only, over a lifetime to calculate the lifetime average daily dose (LADD). However, it might not always be legitimate to assume that a "high" dose over a short period of time would result in the same lifetime cancer risk than the same total dosage received over the whole lifespan. Furthermore, one has to consider that exposures to genotoxic carcinogens early in life might lead to different cancer outcomes anytime later than would exposure restricted to adulthood only. In fact, children seem to be particularly vulnerable to carcinogenic substances, which might be due to several reasons. On the one hand, genotoxic carcinogens are generally more effective in rapidly dividing tissues, since the higher rate of cell division gives less time for either DNA repair or initiated cell death (e.g., apoptosis) and thus results in a higher chance of fixation as mutation. The rate of cell division in brain, liver, and kidney is considerably greater in the first 2 years of life and could be a reason for epidemiological evidence pointing to tumors of the central nervous system (CNS) and kidney as particular concerns for exposures during childhood. Another reason could be the simple fact that mutations early in life have more time left to be later on accompanied by additional mutations that would increase the likelihood of conversion of the affected tissue into malignant tumors due to the greater latency period (Ginsberg 2003). Thus, current methodologies simply prorating the exposure in early life over the entire life span might, indeed, underestimate the actual risk (for further information, see Health Canada 2013). For carcinogens with a mutagenic mode of action, and based on this reasoning, the US-EPA (2005) suggested accounting for different potencies by incorporating age-dependent adjustment factors (ADAFs). For children between age $0-2$ years, an ADAF of 10, while children aged 2 to $<16$, an ADAF of 3 seemed appropriate to the experts. The risk can, therefore, be calculated as follows:

$$
\begin{aligned}
\text { Risk }= & \operatorname{CSF}\left[\frac{1}{\mathrm{mg} / \mathrm{kg} \mathrm{bw} / \text { day }}\right] \times \mathrm{ADAF} \\
& \times \operatorname{SED}[(\mathrm{mg} / \mathrm{kg} \mathrm{bw}) / \mathrm{day}] \times \mathrm{TF},
\end{aligned}
$$

where $\mathrm{CSF}=$ (adult) cancer slope factor of the CMR substance in $\frac{1}{\mathrm{mg} / \mathrm{kg} \text { bw/day }}, \mathrm{ADAF}=$ age-dependent adjustment factor $(0-2$ years: $10 ; 2-16$ years: 3$), \mathrm{SED}=$ systemic exposure dose, calculated according to (1) in $\mathrm{mg} / \mathrm{kg}$ bw/day, and $\mathrm{TF}=$ lifetime fraction, i.e., $1 / 70$ or $2 / 70$ ( 1 or 2 years out of an average life expectancy of 70 years).

The cancer slope factor (CSF) is an upper bound estimate of the increased cancer risk from a lifetime exposure to an agent (US-EPA 2005a). For derivation of the CSF, the LED10 method was proposed by US-EPA in 1996 and is one of the three methods to extrapolate from high doses used in animal experiments to the low doses expected to be relevant for human exposure. The LED10 is defined as dose expected to increase the tumor incidence by $10 \%$ with a lower $95 \%$ confidence limit. The LED10 then serves as a point of departure (POD) for extrapolating outside the observable range, assuming_— in the examples described here_—a linear relationship. Linear extrapolation to low doses is used, for instance, when the mode of action data indicate that the agent is DNA-reactive and has direct mutagenic activity. It is also used as a default when there are insufficient data to evaluate the mode of action. Thus, a straight line is drawn from the POD to the zero dose/response, corrected for background. The slope of the line, called the cancer (or in this case 'oral') slope factor (CSF), expresses the extra risk per unit dose (US-EPA 2005b). It allows comparing the relative cancer potencies of different carcinogens and is expressed as $1 /(\mathrm{mg} / \mathrm{kg}$ bw/day $)$.

The calculated risk according to Eqs. (1) and (2) is an estimation of the so-called additional lifetime cancer risk and corresponds to the number of hypothetical cancer cases in a given population exposed to the dose used for the calculation. For instance, an additional lifetime cancer risk of $5 \times 10^{-4}$ for an SED of $1 \mathrm{mg}$ vinyl chloride $/ \mathrm{kg}$ toy material corresponds to 5 hypothetical cancer cases in 10,000 individuals exposed to a toy material containing this amount of vinyl chloride.

\section{Example 1: Vinyl chloride}

Vinyl chloride (Fig. 1) is a colorless and easily flammable gas with a sweetish smell at higher concentrations. The substance is soluble in alcohol and ether, but only slightly in water. The vast majority of vinyl chloride is used for the production of polyvinyl chloride (PVC) such as for the manufacture of inflatable toys, dolls, and balls. Only a 


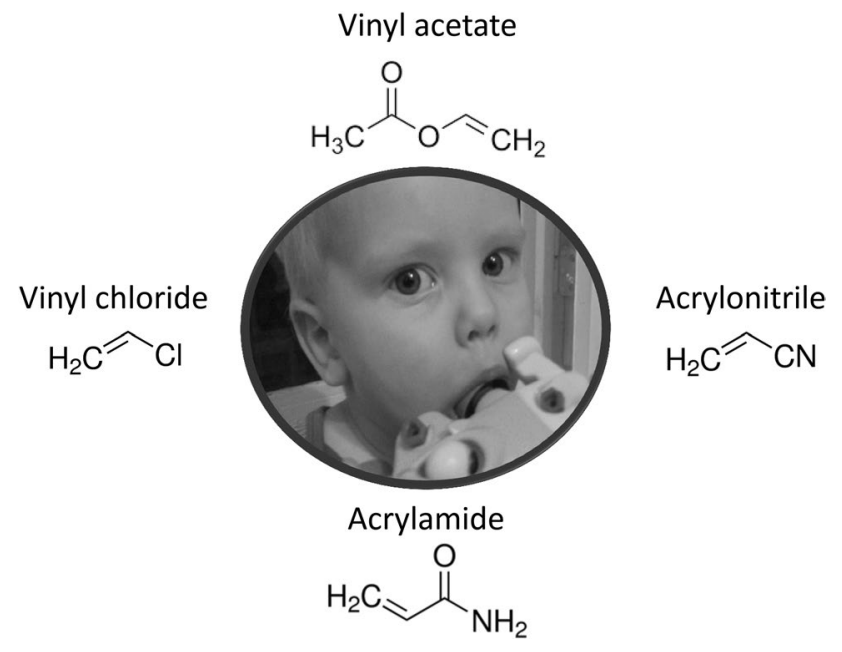

Fig. 1 A picture of a toddler mouthing a toy made of plastic material, surrounded by the chemical structures of the four monomers vinyl acetate, acrylonitrile, acrylamide and vinyl chloride

small extent is used for the copolymerization with acrylic and other vinyl monomers (RÖMPP 2012a).

Vinyl chloride can irritate the eyes and can lead to discoloration and dehydration of the conjunctiva and cornea. It is not sensitizing and the acute systemic toxicity is very low. However, owing to its known carcinogenicity in humans, vinyl chloride is classified as a category $1 \mathrm{~A}$ carcinogen (ECHA 2018a). After chronic exposure to high concentrations of vinyl chloride, an increased incidence of malignant tumors of the liver could be detected in humans (ATSDR 2006). Upon oral ingestion, vinyl chloride is almost completely absorbed (95\%), subsequently metabolized by microsomal (cytochrome P450-dependent) monooxygenases (CYPs), and finally excreted via urine. Since vinyl chloride is converted into its reactive epoxide (chloroethylene oxide) in the endoplasmic reticulum of the hepatocytes, the liver has been shown to be the main target. The epoxide can then interact with adenosine residues of the DNA, subsequently damaging the hepatic sinusoidal cells, resulting in malignant tumors of the hepatic blood vessel wall, the so-called hemangiosarcomas. It is generally assumed that the reactive metabolites chloroethylene oxide and chloroacetaldehyde (which is the rearrangement product of the epoxide) are responsible for the genotoxic and carcinogenic effects due to their DNA alkylating properties (ATSDR 2006). Based on the mechanism of action, vinyl chloride must be regarded as a genotoxic carcinogen, even though it is not classified as a mutagen. The Scientific Committees of the European Commission (i.e., SCCP, SCHER and SCENIHR) are also of the opinion that vinyl chloride is a highly potent genotoxic human carcinogen. Accordingly, in their joint "Opinion on the Use of the Threshold of Toxicological Concern (TTC) Approach for Human Safety Assessment of Chemical Substances with Focus on Cosmetics and
Consumer Products", and on the basis of an additional acceptable lifetime cancer risk of $1 \times 10^{-6}$, a corresponding dose of $1.4 \mathrm{ng}$ vinyl chloride/kg bw/day has been derived (SCCP 2008). Here, an additional safety factor for children under 36 months has not been considered.

According to the TSD, a residual content for the monomer of $1 \mathrm{~g} / \mathrm{kg}$ is permissible in toy materials, while, for FCMs, residual monomers of vinyl chloride must not exceed $1 \mathrm{mg} /$ $\mathrm{kg}$. Assuming a complete release of the monomer after ingestion of $8 \mathrm{mg}$ of polymeric toy material and a $95 \%$ absorption rate, an SED of $1.0 \mu \mathrm{g} / \mathrm{kg}$ bw/day can be calculated for a residual content of vinyl chloride in the polymer according to the TSD using Eq. (1). With a residual content of $1 \mathrm{mg} / \mathrm{kg}$ vinyl chloride in the polymer corresponding to PIM, however, the SED is $1000 \times$ smaller, i.e., $1.0 \mathrm{ng} / \mathrm{kg}$ bw/day.

Comparing the dose that corresponds to an additional acceptable lifetime cancer risk of $1 \times 10^{-6}$ ( 1 out of $1,000,000$ ) with the calculated SED above demonstrates that, in the case of the residual content of $1 \mathrm{~g} / \mathrm{kg}$, as permitted by the TSD, the resulting additional lifetime cancer risk would be $7 \times 10^{-4}$ ( 7 additional cancer cases per 10,000 individuals). Thus, the acceptable risk of $1 \times 10^{-6}$ would be significantly exceeded by approximately three orders of magnitude and, therefore, according to SCHER, "non-acceptable" (2010). On the other hand, the residual content of $1 \mathrm{mg} / \mathrm{kg}$ allowed by PIM leads to an exposure dose which should be sufficiently safe.

In difference to that model, the approach proposed by US-EPA for mutagenic carcinogens according to Eq. (2) includes, on the one hand, the higher sensitivity of children and, on the other hand, the limited lifetime of the mouthing behavior of young children (up to 3 years of age). Using a CSF of 1.5 per $\mathrm{mg} / \mathrm{kg}$ bw/day for continuous lifetime exposure to vinyl chloride from birth, as derived by US-EPA (2000) by applying the LED 10/linear method, the risk of developing cancer can be calculated as follows:

$$
\begin{aligned}
\text { Risk }= & 1.5 \text { per } \mathrm{mg} / \mathrm{kg} \text { bw/day } \times 10 \times 0.001 \mathrm{mg} / \mathrm{kg} \mathrm{bw} / \text { day } \\
& \times 2 / 70(\text { for an age of } 0-2 \text { years }) \\
& +1.5 \text { per } \mathrm{mg} / \mathrm{kg} \text { bw/day } \times 3 \\
& \times 0.001 \mathrm{mg} / \mathrm{kg} \mathrm{bw} / \text { day } \\
& \times 1 / 70(\text { for an age of } 2-3 \text { years }) \\
= & 4.29 \times 10^{-4}+0.64 \times 10^{-4}=4.93 \times 10^{-4}
\end{aligned}
$$

Even with this higher tiered approach, the risk of developing cancer due to the possible ingestion of vinyl chloride via toys (according to limit value of the TSD) is still markedly greater than $1 \times 10^{-6}$ and thus remains unacceptable.

Summarizing the risk assessment for the existing limit value for vinyl chloride in toys, the current regulation does not provide sufficient protection for children while adopting the content limit of FCM to toys would result in sufficient safety. 


\section{Example 2: Acrylamide}

As pure substance, acrylamide (Fig. 1) is a color- and odorless solid, which is readily soluble in water, alcohol, and acetone. It is used as monomer for polyacrylamide, in the production of plastics as well as for polymerization of dispersions, resins and lacquers (RÖMPP 2011a). In the toy sector, the so-called "growing toys" such as dinosaurs in eggs, which grow and eventually burst the eggshell when emerged in water, are made of acrylamide-vinylacetate copolymers.

Uptake of acrylamide into the body can occur orally via mouthing behavior of small children followed by ingestion of toy material. After oral ingestion, acrylamide is resorbed almost completely and distributed rapidly throughout the body due to its high solubility in water. A certain fraction is then being metabolized by CYP2E1 to the mutagenic glycidamide (oxirane-2-carboxamide). Since glycidamide is more reactive toward DNA than the original monomer, it is probably responsible for the mutagenicity and carcinogenicity of the mother compound. Reaction with glutathione (GSH) leads to excretion of mercapturic acid derivatives of acrylamide and/or glycidamide (Settels et al. 2008).

According to the CLP Regulation, acrylamide is classified as toxic for reproduction category 2 as well as carcinogenic and mutagenic category $1 \mathrm{~B}$, thus implying a genotoxic mechanism of action (ECHA 2018b). Acrylamide has been shown to be carcinogenic in chronic studies in rats, where tumors appeared in hormone-dependent organs. On the other hand, mice developed neoplasia of the breast tissue and Harderian glands (accessory lacrimal glands located directly behind the eye in vertebrates that possess nictitating membranes) in addition to tumors of the lungs (EFSA 2015). As a germ cell mutagen, the ALARA principle should apply to acrylamide, and, hence, both the consumer exposure and consequentially the systemic dose as well.

In general it is assumed that the dose-response of genotoxic substances is not associated with a threshold (SCHER/ SCCP/SCENIHR 2009). For some carcinogenic substances with mutagenic properties, however, newer studies indicate that thresholds might, in fact, exist. For instance, a threshold level for the genotoxicity of acrylamide is currently under discussion, but could not be derived from the studies available yet (BfR 2011). Furthermore, it is discussed whether hormonal mechanisms might be important for the carcinogenic effect of acrylamide, as well (BfR 2011).

According to Eq. (1), a residual content of acrylamide of $1 \mathrm{~g} / \mathrm{kg}$ in polymers, as permitted by the Toy Safety Directive, assuming a complete release from $8 \mathrm{mg}$ ingested toy material and $100 \%$ gastrointestinal absorption, would lead to an SED of about $1.07 \mu \mathrm{g} / \mathrm{kg}$ bw/day. The SCCP reports an intake dose of $2 \mathrm{ng} / \mathrm{kg}$ bw/day (SCCP 2008) for acrylamide as being related to an acceptable additional lifetime cancer risk of $1 \times 10^{-6}$. The comparison with the calculated SED for children highlights that, in the case of acrylamide, the content limit value given by the TSD would lead to an additional lifetime cancer risk of $5 \times 10^{-4}$, which is non-acceptable according to SCHER (2010).

For comparison, the risk using the approach of the USEPA has also been calculated. For acrylamide, a CSF of 0.5 per $\mathrm{mg} / \mathrm{kg}$ bw/day (US-EPA 2010) has been reported, demonstrating that its cancer potency is lower than that of vinyl chloride by a factor of 3. Using Eq. (2), the risk of developing cancer can be calculated as follows:

$$
\begin{aligned}
\text { Risk }= & 0.5 \text { per } \mathrm{mg} / \mathrm{kg} \text { bw/day } \times 10 \times 0.00107 \mathrm{mg} / \mathrm{kg} \text { bw/day } \\
& \times 2 / 70(\text { for an age of } 0-2 \text { years }) \\
& +0.5 \text { per } \mathrm{mg} / \mathrm{kg} \text { bw } / \text { day } \times 3 \\
& \times 0.00107 \mathrm{mg} / \mathrm{kg} \text { bw/day } \\
& \times 1 / 70(\text { for an age of } 2-3 \text { years }) \\
= & 1.53 \times 10^{-4}+0.21 \times 10^{-4} \\
= & 1.74 \times 10^{-4}
\end{aligned}
$$

The result using this calculation is in the same range as the more simplified approach above.

In addition, to the discussed content limit for acrylamide in toys corresponding to the TSD, a migration limit has been laid down in the European standard EN 71 part 9 to 11 . The migration of acrylamide should be below the action limit, which is-according to the given analytical method $-0.02 \mathrm{mg} / \mathrm{l}$ (see Table 1). The testing conditions for the migration are based on the assumption that a surface of the toy of about $10 \mathrm{~cm}^{2}$ can be placed in the mouth using $100 \mathrm{ml}$ saliva simulant. Swallowing these $100 \mathrm{ml}$ of saliva would result in an SED of $0.26 \mu \mathrm{g} / \mathrm{kg}$ bw/day, and thus in a level about four times lower than the possible SED according to the content limit of the TSD. Still, the additional lifetime cancer risk would be greater than $1 \times 10^{-6}$ and hence non-acceptable.

Summarizing the risk assessment result for the existing limit values for acrylamide in toys, the current regulation again does not provide sufficient protection for children.

\section{Example 3: Acrylonitrile}

Monomeric acrylonitrile (Fig. 1) is a colorless, highly flammable, and volatile liquid which is used as monomer for the production of polyacrylic fibers or as comonomer with styrene and 1,3-butadiene, such as for the production of LEGO® (RÖMPP 2011b).

Acrylonitrile is rapidly absorbed after oral, dermal, or inhalative exposure, where, according to the literature, oral 
resorption ranges from 90 to $98 \%$ (Woutersen 1998). After its uptake, acrylonitrile is metabolized via two different routes: either glutathione-dependent resulting in the mercapturic acid derivative $\mathrm{N}$-acetyl-S-cyanoethylcysteine or via an oxidative path leading to the epoxide glycidonitrile (2-oxiranecarbonitrile). In animal experiments, acrylonitrile has been shown to be acutely toxic with $\mathrm{LD}_{50}$ (lethal dose $50 \%$ ) values after oral uptake in the range of $72-186 \mathrm{mg} / \mathrm{kg}$ (rat) and $28-48 \mathrm{mg} / \mathrm{kg}$ (mouse). After inhalation, the $\mathrm{LC}_{50}$ (lethal concentration $50 \%$ ) values are $200 \mathrm{mg} / \mathrm{m}^{3} / 4 \mathrm{~h}$ in dogs, $300 \mathrm{mg} / \mathrm{m}^{3} / 4 \mathrm{~h}$ in mice, and between 470 and $1219 \mathrm{mg} /$ $\mathrm{m}^{3} / 4 \mathrm{~h}$ in rats. Here, the formation of cyanide is regarded as being the crucial step of poisoning. Experiences in humans are consistent with the data from animal experiments and confirm the acute toxicity through formation of cyanide and subsequent internal suffocation. Finally, skin contact can also cause poisoning (BAuA 2010).

According to CLP regulation, acrylonitrile is classified as category 1B carcinogen (ECHA 2018c). Although it has not (yet) been classified as mutagenic, the European Chemicals Agency (ECHA) assumes a genotoxic mechanism of action without a threshold (ECHA 2004, 2010). In rats, tumors of the gastrointestinal tract occurred after oral exposure alone, whereas in combination with inhalation, the CNS and the cymbal glands were also affected. In mice, tumors of the gastroesophageal vestibule and the Harderian glands but not in the CNS were observed after oral uptake (BAuA 2010).

According to Regulation (EU) No. 10/2011 (PIM), when acrylonitrile is used for the production of polymeric FCMs, the transition to food shall not be detectable, i.e., the current analytical detection limit of $10 \mu \mathrm{g} / \mathrm{kg}$ of food shall not be exceeded. A limit value for the residual content of acrylonitrile in FCMs has not been defined in the regulation. Conversely, according to the TSD, for children under the age of 36 months, an SED of $1.05 \mu \mathrm{g} / \mathrm{kg}$ bw/day is obtained for a given concentration of $1 \mathrm{~g}$ of residual acrylonitrile per $\mathrm{kg}$ of toy material (ingestion of $8 \mathrm{mg}$ of scrapable toy material, complete release from toy material and subsequent gastrointestinal absorption of $98 \%$ ).

The Scientific Committees of the European Commission are also assuming a genotoxic mode of action for acrylonitrile. Using the concept of linear extrapolation, a supposedly adequate procedure for genotoxic carcinogens, the SCCP has calculated an uptake dose of $1.9 \mathrm{ng} / \mathrm{kg}$ bw/day as being associated with an acceptable additional lifetime cancer risk of $1 \times 10^{-6}$ (SCCP 2008). This dose is exceeded by a factor of 500 from the SED of $1.05 \mu \mathrm{g} / \mathrm{kg}$ bw/day permitted in toys, therefore, associated with an additional lifetime cancer risk of $5 \times 10^{-4}$. Following the refined US-EPA model corresponding to Eq. (2), the risk of developing cancer using a CSF for acrylonitrile of 0.54 per $\mathrm{mg} / \mathrm{kg}$ bw/day (US-EPA 1999) can be estimated as follows:
Risk $=0.54$ per $\mathrm{mg} / \mathrm{kg}$ bw $/$ day $\times 10 \times 0.00105 \mathrm{mg} / \mathrm{kg}$ bw $/$ day

$$
\begin{aligned}
& \times 2 / 70(\text { for an age of } 0-2 \text { years })+0.54 \text { per } \mathrm{mg} / \mathrm{kg} \text { bw/day } \\
& \times 3 \times 0.00105 \mathrm{mg} / \mathrm{kg} \text { bw/day } \times 1 / 70(\text { for an age of } 2-3 \text { years }) \\
= & 1.62 \times 10^{-4}+0.24 \times 10^{-4}=1.86 \times 10^{-4}
\end{aligned}
$$

In addition, this higher tiered approach confirms that the content limit allowed for acrylonitrile in toys is resulting in an additional lifetime cancer risk clearly exceeding the risk value of $1 \times 10^{-6}$ and thus still constitutes an unacceptable risk according to SCHER (SCHER 2010).

\section{Example 4: Vinyl acetate}

Monomeric vinyl acetate (Fig. 1) is a colorless, flammable, reactive, and partially water soluble liquid. In small quantities, it has a sweet, fruity smell which, however, can become sharp and irritating in large quantities. Vinyl acetate is a basic module for the production of a wide variety of polymers, mainly polyvinyl acetate (PVAC) and copolymers used in many commercial and industrial products, such as ethylene-vinyl acetate copolymers (EVA) in puzzle mats (RÖMPP 2012b).

According to ECHA, the content of residual vinyl acetate monomer in homopolymer and copolymer depends on the product, spanning a wide range of reported values of less than $5 \mathrm{ppm}$ to up to $6000 \mathrm{ppm}$. A quantitatively weighted median value for the monomer residue content of roughly $3000 \mathrm{ppm}(0.3 \%)$ is given in the literature (ECHA 2008).

Vinyl acetate irritates the upper respiratory tract, the skin, and the eyes; contacts with vapors and liquids should, therefore, be avoided (ECHA 2008). Vinyl acetate is not considered to be a skin sensitizer but is classified as a category 2 carcinogen according to CLP Regulation, meaning that mixtures containing $1 \%$ or more vinyl acetate have to be classified and labeled as carcinogenic (ECHA 2018d).

ECHA estimates that $50 \%$ of the ingested amount will be absorbed in the gastrointestinal tract and subsequently enzymatically hydrolyzed into acetic acid and acetaldehyde, the latter of which being regarded as the toxicologically critical metabolite with respect to the carcinogenic potential (ECHA 2008). Although acetaldehyde is thought to be a genotoxic metabolite, a threshold dose appears to exist for vinyl acetate below which no tumor formation occurs (SCHER 2008). Chronic drinking water studies in rats (Umeda et al. 2004) found a dose-dependent increase in carcinomas in the upper gastrointestinal tract of female rats at $\geq 400 \mathrm{ppm}$ ("lowest observed adverse effect level", LOAEL $=31 \mathrm{mg} / \mathrm{kg}$ bw/day for female and $21 \mathrm{mg} / \mathrm{kg}$ bw/day for male rats, respectively), of which the latter was suggested to be used as POD for oral risk assessment (ECHA 2008; Health Canada 2008). A threshold mechanism for tumor formation in the gastrointestinal tract following oral administration seems, therefore, likely (ECHA 2008). 
Consumer exposure mainly occurs due to emissions from carpets, paints, and adhesives. The total exposure to all sources is estimated to be between 5 and $20 \mu \mathrm{g} / \mathrm{kg}$ bw/ day (ECHA 2008; SCHER 2008). For vinyl acetate, a tolerable daily intake (TDI) value of $0.2 \mathrm{mg} / \mathrm{kg}$ bw has been established (ECHA 2008). According to Regulation (EU) No 10/2011 (PIM), based on this TDI, the specific migration limit for the use of vinyl acetate as FCM is $12 \mathrm{mg}$ per $\mathrm{kg}$ of food. A residual concentration limit of vinyl acetate allowed for FCM has not been established though.

According to the TSD, a residual content of $10 \mathrm{~g} / \mathrm{kg}$ in toy material, a value probably larger than what is found in real products (see above), is permissible for vinyl acetate due to its classification as category 2 carcinogen. After swallowing $8 \mathrm{mg}$ of toy material and assuming a complete release, a $50 \%$ oral resorption, and a body weight of $7.5 \mathrm{~kg}$, a corresponding SED of $5.33 \mu \mathrm{g} / \mathrm{kg}$ bw/day is being calculated. Therefore, the exposure of children via toys can be in the same range as the total exposure to all other sources estimated by ECHA. As vinyl acetate is one of the few cases of genotoxic carcinogens with a threshold value, the TDI value can be used for risk assessment. As a result, exposure to toys meeting the proposed conditions constitutes less than 5\% of the TDI. Accordingly, a Margin of Safety (MoS) of $>100$ is regarded as being sufficiently safe. Since no NOAEL ("no observed adverse effect level") had been derived from animal experiments yet, the $\mathrm{MoS}$ can be estimated from the LOAEL ( $=21 \mathrm{mg} / \mathrm{kg}$ bw/day) using an uncertainty factor of $1 / 3(\mathrm{LOAEL} / 3 \times \mathrm{SED})$. This leads to the calculated MoS level of: $21,000 / 3 \times 5.33=1313$. In conclusion, the limit value of the TSD for vinyl acetate can be regarded as being sufficiently safe.

\section{Recommendations/suggestions for further proceedings}

The risk assessments exemplified for the four monomers above demonstrate that for genotoxic carcinogens without a threshold value, the residual content permitted in toys according to the TSD, i.e., $0.1 \%$ for category $1 \mathrm{~A}$ or $1 \mathrm{~B}$ and $1 \%$ for category 2 carcinogens, respectively, is associated with an additional lifetime cancer risk, which is exceeding the value of $1 \times 10^{-6}$. According to SCHER, this is unacceptable. Only for vinyl acetate, which is a genotoxic carcinogen with a threshold value, the residue concentration allowed by TSD can be regarded as being sufficiently safe. On the other hand, for vinyl chloride in addition to a specific migration limit, also a content limit value of $1 \mathrm{mg} / \mathrm{kg}$ is laid down in Regulation (EU) No 10/2011 (PIM) for the residue of monomers in the final product. These content limits, when applied to toys, would lead to systemic exposure doses, which are associated with an additional lifetime cancer risk below the value of $1 \times 10^{-6}$ and thus, would be acceptable according to SCHER. Although it is not shown in detail here, this also holds true for some other carcinogens, for instance 1,3-butadiene and epichlorohydrin, since the content limit laid down in the PIM is lower by a factor of 1000 when compared to the TSD. Therefore, for some genotoxic monomers, the application of the content limit of the PIM to toys would result in a sufficient protection level for young children.

One approach to estimate whether the risk of developing cancer due to ingestion of polymeric toy material is acceptable or not was by simply comparing the calculated SED with the dose that corresponds to an additional lifetime cancer risk of $1 \times 10^{-6}$. If the calculated systemic exposure dose exceeded the value taken from the literature, the risk of developing cancer can be regarded as unacceptably high. However, these doses were derived, in most cases, from animal studies investigating exposures in sexually mature animals only, thus not reflecting that young children might be more susceptible to genotoxic carcinogens than adults.

Therefore, in a second, more sophisticated approach assessing genotoxic carcinogens, we followed the guidance as proposed by US-EPA by incorporating ADAFs for the higher susceptibility of young children and the fraction of exposure time via toys of young children relative to a lifespan of 70 years, although, in fact, cancer can manifest any time earlier in life. As a matter of fact, the calculated additional lifetime cancer risk values based on the content limits of the TSD were lower using this approach, but the conclusions remained the same.

In any case, since the actual residual contents of the different monomers in polymeric toy materials are not known to the authors, the potential health risks calculated here remain related to the residue content limit value allowed by the TSD or the PIM. To be on a safe side, we, therefore, recommend defining substance-specific limit values for the carcinogenic monomers used for the production of toys and to include them in Appendix C of Annex II of the TSD, and that this should be derived based on compound-specific risk assessments. Since their inclusion in Appendix C is not expected in the near future, we currently stay with the recommendation to prolongate the exemption of the CMR use ban in toys for those materials that are in compliance with the provisions for FCMs according to Regulation (EC) No. 1935/2004.

\section{References}

ATSDR (2006) Toxicological profile for vinyl chloride. https://www. atsdr.cdc.gov/toxprofiles/tp20.pdf. Accessed 15 Feb 2018

BAuA (2010) Expositions-Risiko-Beziehung zu Acrylnitril. http:// www.baua.de/de/Themen-von-A-Z/Gefahrstoffe/TRGS/ pdf/910/910-acrylnitril.pdf?__blob=publicationFile $\& v=1$. Accessed 15 Feb 2018 
BfR (2011) Stellungnahme Nr. 043/2011 des BfR vom 29. Juni 2011, ergänzt am 21. Januar 2013. Acrylamid in Lebensmitteln. http://www.bfr.bund.de/cm/343/acrylamid-in-lebensmitteln.pdf. Accessed 15 Feb 2018

ECHA (2004) Risk assessment summary report on acrylonitrile. https ://echa.europa.eu/documents/10162/b05f71cc-e1b9-4d15-8f82e7b3a426eec5. Accessed 15 Feb 2018

ECHA (2008) Summary risk assessment report on vinyl acetate. https:// echa.europa.eu/documents/10162/6434698/orats_summary_vinyl acetate_en.pdf. Accessed 15 Feb 2018

ECHA (2010) European Union risk assessment report on acrylonitrile. https://echa.europa.eu/documents/10162/22bf49d3-e951-44b8a45a-6973d3dc62f6. Accessed 15 Feb 2018

ECHA (2018a) Brief profile chloroethylene. https://echa.europa.eu/de/ brief-profile/-/briefprofile/100.000.756. Accessed 15 Feb 2018

ECHA (2018b) Brief profile acrylamide. https://echa.europa.eu/de/ brief-profile/-/briefprofile/100.001.067. Accessed 15 Feb 2018

ECHA (2018c) Brief profile acrylonitrile. https://echa.europa.eu/de/ brief-profile/-/briefprofile/100.003.152. Accessed 15 Feb 2018

ECHA (2018d) Brief profile vinyl acetate. https://echa.europa.eu/de/ brief-profile/-/briefprofile/100.003.224. Accessed 15 Feb 2018

EFSA CONTAM Panel (EFSA Panel on Contaminants in the Food Chain) (2015) Scientific opinion on acrylamide in food. http:// onlinelibrary.wiley.com/doi/10.2903/j.efsa.2015.4104/pdf. Accessed 15 Feb 2018

EN (2007) 71 - 9:2007-09 (European Standard) Safety of toys-Part 9: organic chemical compounds-requirements; German version EN 71-9:2005 + A1:2007; Beuth Verlag. http://www.beuth.de/ en/standard/din-en-71-9/100555489. Accessed 15 Feb 2018

EU (2004) Regulation (EC) No 1935/2004 of the European Parliament and of the Council of 27 October 2004 on materials and articles intended to come into contact with food and repealing Directives 80/590/EEC and 89/109/EEC. http://eur-lex.europa.eu/ legal-content/EN/TXT/PDF/?uri=CELEX:02004R1935-20090 $807 \&$ qid $=1519208853845 \&$ from $=E N$. Accessed 15 Feb 2018

EU (2008) Regulation (EC) No 1272/2008 of the European Parliament and of the Council of 16 December 2008 on classification, labelling and packaging of substances and mixtures, amending and repealing Directives 67/548/EEC and 1999/45/EC, and amending Regulation(EC) No 1907/2006. http://eur-lex.europa.eu/ legal-content/EN/TXT/PDF/?uri=CELEX:02008R1272-20170 $601 \&$ qid $=1519209074810 \&$ from $=E N$. Accessed 15 Feb 2018

EU (2009) Directive 2009/48/EC of the European Parliament and of the Council of 18 June 2009 on the safety of toys. http://eur-lex.europ a.eu/legal-content/EN/TXT/PDF/?uri=CELEX:02009L0048-20171 $124 \&$ qid $=1519209229708 \&$ from $=E N$. Accessed 15 Feb 2018

EU (2011) Commission Regulation (EU) No 10/2011 of 14 January 2011 on plastic materials and articles intended to come into contact with food. http://eur-lex.europa.eu/legal-content/EN/TXT/ HTML/?uri=CELEX:02011R0010-20180208\&qid=1519209327 $266 \&$ from $=$ EN. Accessed 15 Feb 2018

EU (2017a) Commission Directive (EU) 2017/898 of 24 May 2017 amending, for the purpose of adopting specific limit values for chemicals used in toys, Appendix C to Annex II to Directive 2009/48/EC of the European Parliament and of the Council on the safety of toys, as regards bisphenol A. http://eur-lex.europ a.eu/legal-content/EN/TXT/HTML/?uri=CELEX:32017L0898 $\&$ from $=$ EN. Accessed 15 Feb 2018

EU (2017b) Commission Directive (EU) 2017/774 of 3 May 2017 amending, for the purpose of adopting specific limit values for chemicals used in toys, Appendix C to Annex II to Directive 2009/48/EC of the European Parliament and of the Council on the safety of toys, as regards phenol. http://eur-lex.europa.eu/legal -content/EN/TXT/HTML/?uri=CELEX:32017L0774\&from=EN. Accessed 15 Feb 2018
Ginsberg GL (2003) Assessing cancer risks from short-term exposures in children. Risk Anal 23(1):19-34

Health Canada (2008) Screening assessment for the challenge acetic acid ethenyl ester (vinyl acetate monomer). https://www.ec.gc. ca/ese-ees/E41E17F4-59C5-44CC-94F3-155CE6094238/batch 2_108-05-4_en.pdf. Accessed 15 Feb 2018

Health Canada (2013) Interim guidance on human health risk assessment for short-term exposure to carcinogens at contaminated sites. http://publications.gc.ca/collections/collection_2013/sc-hc/H14411-2013-eng.pdf. Accessed 15 Feb 2018

RÖMPP (2011a) Online Enzyklopädie zur Chemie. Acrylamid. https ://roempp.thieme.de/roempp4.0/do/data/RD-01-00620. Accessed $15 \mathrm{Feb} 2018$

RÖMPP (2011b) Online Enzyklopädie zur Chemie. Acrylnitril. https ://roempp.thieme.de/roempp4.0/do/data/RD-01-00634. Accessed $15 \mathrm{Feb} 2018$

RÖMPP (2012a) Online Enzyklopädie zur Chemie. Vinylchlorid. https ://roempp.thieme.de/roempp4.0/do/data/RD-22-00805. Accessed 15 Feb 2018

RÖMPP (2012b) Online Enzyklopädie zur Chemie. Vinylacetat. https ://roempp.thieme.de/roempp4.0/do/data/RD-22-00794. Accessed 15 Feb 2018

SCCP (2008) Opinion on the use of the threshold of toxicological concern (TTC) approach for human safety assessment of chemical substances with focus on cosmetics and consumer products. SCCP/1171/08. http://ec.europa.eu/health//sites/health/files/scientific_committees/ consumer_safety/docs/sccs_o_092.pdf. Accessed 15 Feb 2018

SCHER (2008) Risk assessment report (RAR) of vinyl acetate. https ://ec.europa.eu/health/archive/ph_risk/committees/04_scher/docs/ scher_o_108.pdf. Accessed 15 Feb 2018

SCHER (2010) Risk from organic CMR substances in toys. http:// ec.europa.eu/health//sites/health/files/scientific_committees/envir onmental_risks/docs/scher_o_121.pdf. Accessed 15 Feb 2018

SCHER/SCCP/SCENIHR (2009) Scientific opinion on the risk assessment methodologies and approaches for genotoxic and carcinogenic substances. http://ec.europa.eu/health/ph_risk/committees /04_scher/docs/scher_o_113.pdf. Accessed 15 Feb 2018

Settels E, Bernauer U, Palavinskas R, Klaffke HS, Gundert-Remy U, Appel KE (2008) Human CYP2E1 mediates the formation of glycidamide from acrylamide. Arch Toxicol 82:717-727

Umeda Y, Matsumoto M, Yamazaki K, Ohnishi M, Arito H, Nagano K, Yamamoto S, Matsushima T (2004) Carcinogenicity and chronic toxicity in mice and rats administered vinyl acetate monomer in drinking water. J Occup Health 46:87-99

US-EPA (1999) Integrated risk information system (IRIS) on acrylonitrile. https://cfpub.epa.gov/ncea/iris/iris_documents/documents/ subst/0206_summary.pdf. Accessed 15 Feb 2018

US-EPA (2000) Integrated risk information system (IRIS), chemical assessment summary vinyl chloride. https://cfpub.epa.gov/ ncea/iris/iris_documents/documents/subst/1001_summary.pdf. Accessed 15 Feb 2018

US-EPA (2005a) Supplemental guidance for assessing susceptibility from early-life exposure to carcinogens. https://www3.epa.gov/ airtoxics/childrens_supplement_final.pdf. Accessed 15 Feb 2018

US-EPA (2005b) Guidelines for carcinogen risk assessment. https:// www.epa.gov/sites/production/files/2013-09/documents/cance r_guidelines_final_3-25-05.pdf. Accessed 15 Feb 2018

US-EPA (2010) Toxicological review of acrylamide. https://cfpub.epa. gov/ncea/iris/iris_documents/documents/toxreviews/0286tr.pdf. Accessed 15 Feb 2018

World Health Organisation (2002) Health implications of acrylamide in food. Report of a Joint FAO/WHO consultation. http://apps.who.int/ iris/bitstream/10665/42563/1/9241562188.pdf. Accessed 15 Feb 2018

Woutersen R (1998) Toxicological profile of acrylonitrile. Scand Journal of Work, Environment \& Health. vol 24, Supplement 2. The mortality of acrylonitrile workers-new evidence and a review of the old, pp 5-9 